\title{
Brand Personality of the Premier League of Iran's Soccer - Strategies and Consequences
}

\author{
${ }^{1}$ Fakhrossadat Tabatabaeian*, ${ }^{2}$ Mohammad Khabiri, ${ }^{1}$ Mehdi Rasooli
}

${ }^{1}$ Sport Management Department, Sport Sciences Research Institute of Iran, Tehran, Iran. ${ }^{2}$ Sport Management Department, Faculty of Sport Sciences, University of Tehran, Tehran, Iran.

\begin{abstract}
Background. Brand Personality (BP) is one of the most commonly used concepts in marketing literature, and academicians and marketers believe in its benefits. Today, brand personality plays an important role in strategic management and it is considered as one of the most important tactics of an organization to gain a Competitive Advantage (CA). Objectives. This paper aims to investigate the factors that cause the growth and development of brand personality of the Premier League of Iran's Soccer and identify the actions and interactions resulting from this phenomenon, and the results and consequences of the use of these actions and interactions. Methods. To this end, the present study was conducted in the framework of a qualitative approach using the Grounded Theory (GT) method. The data collection tools included semi-structured in-depth interviews. Using the purposive sampling method, 23 individuals including academic elites, experts familiar with brand management issues in sports, certified managers and sports practitioners in soccer league organization, club managers, and sports media and brand specialists, were selected and interviewed. The obtained data were analyzed using the three-step process of open, axial and selective codings. Results. Based on the results obtained from the open coding of the qualitative interviews, 103 attributes were identified with regards to the factors that shape Premier League brand personality. The findings indicate that there are 83 effective attributes in the brand personality phenomenon and its growth and development. The required strategies and consequences of the brand personality in the Premier League of Iran's Soccer were classified into 9 concepts, including organizational attributes, team attributes, function, fans, direct resources, indirect resources, performance attributes, non-performance attributes, brand strength and relationships. Conclusion. Considering the key concepts associated with the formation of the brand personality of Premier League, namely the organizational attributes, team attributes, function and fans, executives and planners of the premier league of soccer can act and interact based on the provided strategies, so as to obtain the expected results, that is, emergence of the brand personality of premier league, and the consequences of this emergence, such as two-way relationship with the customers and potential beneficiaries, and to strengthen the brand success variables such as the image, attitude, purchase preferences and services provided by the league.
\end{abstract}

KEY WORDS: Brand Personality, Soccer, Self-Congruity, Self-Expression, Brand Relationship.

\section{INTRODUCTION}

Brand Personality (BP) is a popular and wellknown subject for academicians and researchers in management field $(1,2,3,4,5,6)$. Brand personality, a subject from the fields of psychology and sociology, was first introduced and brought to the marketing field by Aaker (7). Aaker (7) scientifically presented the human consideration of brand and considered brand

*. Corresponding Author:

Fakhrossadat Tabatabaeian

E-mail: tabatabaeian2009@yahoo.ca 
personality to have a number of human attributes. She introduced the anthropomorphism and animism theory in response to consumers' acceptance of the description in human beings in brand personality, and designed a fivedimensional model (including sincerity, competence, excitement, ruggedness and sophistication). Despite the criticisms made about her model, she was successful in constructing some fundamental foundations for further research in this field.

The concept of brand personality was also highly welcomed in sports marketing $(8,9,10$, 11); and human traits and attributes were also applied to describe sports teams (e.g., a successful and high-flying team) (9); these attributes can be mentioned for a team in a variety of ways, and they would help to increase the fans and then attract more team sponsors (12), especially if it is a unique one, as it will be a means to increase the brand awareness and attachment (7).

For better understanding of brand personality, two criteria can be considered (13), namely, brand positioning and brand identification. The brand's position is considered from the consumers' point of view, and it is about how consumers interpret and see the brand (14). This interpretation, however, is a notion that a consumer usually has from the previously conducted activities of organizations, such as the pricing practices, distribution method, country of origin (geographic origin) and marketing campaigns (15). In sports field, research has shown that previous backgrounds such as logo design, coaches, and teamwork and team performance can be effective in creating a brand image for the customers. However, brand identity views the brand personality from the organization's perspective. What is the ideal image of the organization from the brand personality and what values does it have? Certainly, the brand personality of an organization reflects the values of that organization (16). Organizations spend a lot of money to create a distinct personality in the minds of consumers (15). However, given that the consumers' perception of brand personality is filtered through a variety of personal experiences, market factors, and cultures, thus, organizations and marketers can only control about half of their brand's destiny (17). Hence, a significant amount of the brand personality type will be out of the control of management. Therefore, sports marketers need to be aware of the elements that make up a favorite brand for them (15). Accordingly, sports managers and planners can make the behaviors and marketing activities of their sports organization more attractive and distinctive if they seek to identify the sources and areas for creating their own brand personality and examine the inner layers. If a sport club can design its own personality in accordance with its goals and transfer it well into the minds of its customers, then, this personality will increase the brand preferences, brand loyalty, and customer's relationship with the brand of that club or sport center (18). Increase in the positive attributes of the brand personality of teams (for instance, having star players with a good reputation) can also affect the team identity and increase the team-related consumption behaviors in the consumers (19).

Brand personality can operate based on the congruity principle. Researchers like Klipfel and Barclaly (20) considered self-congruity as a function and determining factor of brand personality. The idea that customers choose brands with the highest degree of personality similarity or so-called self-congruity has already been raised by Sirgy (21). He showed that if customers fit into what they consider to be personally relevant to what the brand offers them, they would go for that brand. Indeed, Sirgy (22) stated that the match of the image of a brand personality, formed in the mind of a customer, with the customer's self-concept, can have a great impact on the customer preferences, purchase intention, product profitability, and ultimately, brand loyalty. Brand can also be in a dynamic relationship with the consumer (23). This relationship between the consumer and the brand would be a source of self-efficacy, self-esteem and self-knowledge, and these three important points provide a comprehensive understanding of the brand relationships (24). This relationship is important and brings about the norms of consumer social relations (25). In fact, the driving force behind the brand personality includes branding activities and the country of origin due to its relationship with the pleasurable benefits of brand (26). Meanwhile, "brand personality" in sports field is different from that in other fields due to the unpredictable nature of the results of 
sports events and the co-operation of the teams during competition (such as the competition between the two rival teams) (27).

Among the research findings on the brand personality of premier league, the results of the study conducted by Shafaie et al. (using the exploratory factor analysis method) can be mentioned, in which seven dimensions of brand personality of soccer teams were introduced from the viewpoints of fans, and includes uniqueness, perfection, excitement, distinctiveness, stunning, classic and success. However, there are two major weak points in the methodology of this research; first, the necessary research considerations were not taken into account in collection of the attribute sets; and next, the information was also collected using the questionnaires completed by excited spectators inside the stadium. Another study was conducted by Asadollahi et al. (5), on the factors affecting the brand personality of Iran's sports clubs; the results indicated seven influencing factors: symbolism, loyalty, originality, attractiveness, credibility, excitement and emotion. Asadollahi considered the factor "attractiveness" as one of the most important factors; this factor determines the quality of brand personality, but does not specify its sources.

In this regard, few studies conducted so far are limited to the determination and evaluation of brand personality attributes in sport teams. Given that these personality attributes are not the result of systematic and guided activities and they are formed only on the basis of the temporary emotions of the fans, it is obvious that they cannot be in line with the macro goals of the premier league of Iran's soccer. Perhaps, in this way, there is no good match between the perceptions of the fans and the image of the League Organization. Therefore, managers and planners of the premier league need to be more resourceful to attract and retain huge social capital of Iran's soccer. As a result, the present study is the first (both inside and outside the country) to identify and investigate the factors that shape the brand personality of premier league of Iran's soccer. It is hoped that the strategies and consequences obtained from this study can be useful as the keys for the staff and line managers to create a fascinating and distinctive personality, and help league managers to create an interactive relationship with the customers (fans, supporters, spectators and media).

\section{MATERIALS AND METHODS}

Participants. The statistical population of the study is 23 experts including faculty members in the fields of sports management, sports sociology, sports psychology, as well as football experts, managers and executive professionals with experience in the upper and middle levels of soccer league organization, premier league soccer clubs, football federation and association, and experts in the field of brand and active sports media.

Table 1. Research Samples (interviewees)

\begin{tabular}{cc}
\hline Faculty members & 8 \\
\hline $\begin{array}{c}\text { Managers and executives of } \\
\text { the organization and clubs }\end{array}$ & 8 \\
\hline Sports media & 3 \\
\hline Experts in the field of brand & 4 \\
\hline
\end{tabular}

Research Tool. The research tool included semi-structured in-depth interviews;

Data Collection. Sampling was done using the purposive and snowball sampling method and continued until the research team concluded that the new information is a repetition of the previous one and no other new information was obtained (theoretical saturation); finally, 23 qualitative interviews were conducted. The interviews were conducted once, and each one was investigated before conducting the next one, and the next interview was done based on the findings of the previous one. To analyze the findings, the systematic approach attributed to Strauss and Corbin (1990) was applied during the three stages of open, axial and selective codings. To ensure validity of the study, measures like matching by the members, peer reviews and participatory investigation were performed.

\section{RESULTS}

From the implementation of qualitative interviews, 83 attributes were obtained for the main categories of growth and development (causal conditions) of the league brand personality. By analyzing these attributes and summarizing the findings based on the index of relevance, their similarity with each other and the constant comparative, these attributes were finally classified into 9 concepts or subcategories, including organizational attributes, team 
attributes, function, fans, direct resources, indirect resources, performance attributes, non- performance attributes, brand strength and relationships.

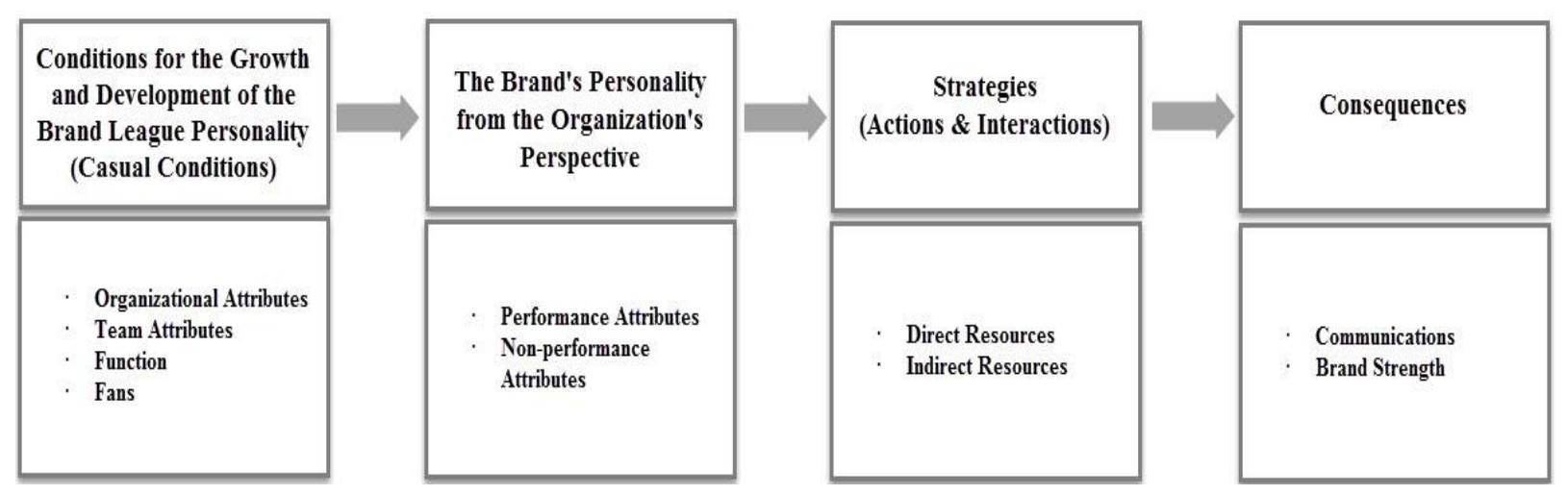

Figure 1. The Route of the Formation of the Consequences.

The categories: "team attributes", "organizational attributes", "function", "fans and their identities", together with their attributes, were identified as factors that lead to the development and creation of brand personality of the league, which were dealt with in the following.

1. Team Attributes: The desirable level of quality of the competition, attractiveness, competitive balance and endorsement are the attributes raised in this regard. It can be said that the better the quality of the competitions, the more attractive it will be to spectaculars and fans, and if a spectator is satisfied with the game quality, he will be more likely to attend the team's future matches. The interviewee stated that:

$H .$, J: "attraction and diversity." Nowadays, people thirst for new experiences and the sports fields are the best places to gain these experiences, where sports events are held.

- Unpredictable results are attractive to people.

Based on this research, the attractiveness of a sport team has a significant effect on the identity of the team's fans. Many of the studies conducted in the field of soccer and its league in Iran, tend to determine the factors affecting attractiveness, and enhance the team identity. This issue indicates the need to identify the factors affecting the attractiveness of soccer companies to the researchers in this area, namely, history, tradition, valid background of clubs $(24,25)$, playing style, record and history of team successes (23).
"Competitive balance" is another attribute identified to increase the attractiveness of soccer matches. The more the competitive power of the teams that make the league, the more difficult is the prediction of the matches, and the more attractive will be the league (24).

Together with the staff, managers and consumers of brand, brand endorsements are also factors that affect the perception of brand personality, which are also considered as the most effective advertisement method in this area (25). The team identity, which is one of the most significant aspects of the sport team development, is among other attributes of the factors recognized. Shih-Hao et al. (26) also held that the attractiveness of club brand personality and the creation of team identity for fans are the main factors in the trust of fans on their beloved team.

2. Organizational Attributes: Organizational attributes are other causal conditions identified, which include the interior and exterior infrastructure of the stadium (e.g., proximity to the green area and the park, its design, the special guest room, the size of the screen in the stadium, parking facilities, the issue of transportation to the track and the cover of the stadium roof) and discipline in holding matches, presence of reputed and elite referees, the reputation of sponsors, having a consistent and unique name, having standards and developed frameworks, transparency in affairs, identifying the value of the brand and elements of the league, tradition and history, leading organizations such as League 
organization and Soccer Federation, clubs, and the executive sector. Shortcomings such as poor conditions in soccer stadiums, inappropriate time schedule, lack of necessary frameworks (27), uncertainty in investment in the country's soccer industry, financial sponsor character, lack of developing strategic plans and marketing operations, state-owned clubs, and lack of enforcement of copyright law in the country, can have adverse effect on brand personality of the league (4).

3. Performance and Function: Supervision of the league on clubs' contracts concluded with players, clarification of contracts in the league, League records (Asian and International), league level, advertisements, league connections with fans, league service performance, selected performance processes and its results (e.g., supporting specific supporters and advocates, litigation management, time management: specific and consistent time to buy tickets, entrances, entertainments) and customers' perception of the quality stability, are the signs obtained in this regard.

4. Fans: The presence of fans in the stadium is undoubtedly the most significant part of a sport event. The presence of many sports enthusiasts in the matches and fanatics of the teams has made soccer industry a popular and influential industry. No fan means there's no need to play games on $\mathrm{TV}$ and address the media rights.

Here, the "brand personality of the premier soccer league", which has some attributes associated with performance and nonperformance attributes (e.g., combativeness, ambition, power-seeking, diversity-seeking, originality, truthfulness, being emotional, revoking pride, success, being technical, professionalism, elite, emotion, having a high level, attraction, beauty, spirit of firmness, being prestigious, combativeness, fair and heroic play, ethics, giving joy, differentiation and professionalism) were identified as the core categories. In fact, in order to create a brand personality, the manager should be able to mix the brand with an attractive personality and relevant to consumer's self-concept, shaping it through brand communication and interaction with consumers. For instance, the features of the intended product or service (e.g., success, team performance, star player, head coach, manager, logo and club colors, stadiums, traditions and club history, club culture and values, fans, supporters, region and city or country) shape perceptions in the minds of customers/fans about the brand, which in fact manifests brand personality.

Strategies, Actions and Interactions: The present research presents the strategies developed to shape and create a desirable personality for the brand in direct and indirect resources. Direct sources include a set of human features that are associated with the permanent customers of premier league brand, staff of league organization, managers, creditors and endorsers of the premier league, and customer's comments on the physics, performance and tangible aspects of the league, namely, product prices, appearance; distribution and promotion mode that is experienced by consumers include the indirect resources affecting brand personality.

The category, communication, with its attributes that emerged as the consequence and included the following signs: establishing further communication with customers, fans and more loyalty, more profit and revenue, customer identification ability, increased league brand power, promotion of the league level, creation of more correlation (in social, cultural, political context), entry into international arenas, political, social, cultural and economic effects. An example of interviews is provided in this regard:

Dr. H. E. about the brand consequences: This is the effect of the brand personality, which has political, social, economic and cultural effects.

In order to keep the current fans and attract new ones, the league organization needs to look for effective management mechanisms so that they can work through various channels to increase the quality of communication with fans and increase their longevity. This concept was confirmed by the results of the study conducted by Carlson et al. (13) and Karjaluoto et al. (28).

\section{DISCUSSION}

In search for a larger share of the customer market, managers and marketers set many of their marketing activities. Sport industry planners are no exception to this, and they attempt to utilize successful strategies to attract and retain their customers. The brand personality can be effective as a strategy and a significant management approach to the brand, aiding in achieving 
managerial purposes. Therefore, with regards to the league brand personality, where the country's largest sporting events occur, it is necessary that the League organization employ senior and professional human resources, such as certified and justified managers, trained and justified staff in line with the brand goals of the organization, so that it can convert its values directly into behaviors by these human resources (29). The employees and managers involved have the most direct ways to provide leagues brand personality. Most interviewees believed that government managers lack the necessary job sensitivities for private sector managers, and because of their many dependencies in the government, they lack commercialization and revenue concerns in their work schedule, and do not spend time on the laws of the real brand. With the emergence of each political wing, they are also replaced; thus, this instability does not provide them with the opportunity for improvement.

When defining frameworks and standards, the league organization activities and actions will be conducted in accordance with these requirements in a transparent manner, and no one will behave individually from managers to players, but are all activate in line with goals of the organizations in a synergic way. The league will provide more powerful reminiscent of itself, with a constant and unchanged name derived from a particular culture or belief in a particular people or region, and a history of glory and success, together with attractive stadiums and special architectures.

The optimal level of the matches, the display of attractive and high quality games, constant stability and order, adequate supervision over concluding the clubs' contracts with players, spectaculars' service level, behavioral stability in organizational performance, wide advertisement, fans' personality and identity, reputation of sponsors, maintenance of long contracts with full security and distinct marketing activities can all provide the grounds for attractive personality and indicate a concept that was discussed in the context of all interviewees.

In addition, the presence of successful and popular clubs in the league competition can greatly assist in the promotion of league level. League directors and managers can respect the fans by providing more services with affordable costs and easy access to buy tickets, easy access to the stadium and match courts, access to public parking lots, favorable entertainment conditions in stadiums, and activities of this kind. This also creates proud moments for spectators by holding magnificent opening and closing events, and by assigning restaurants and cafes to fans, establishing museums and sports shops to sell and distribute goods and sports symbols of the league, especially distinct marketing activity. Each club and league must be able to communicate properly and accurately through its media sector, which is the means of communication with the client, through which it can broadcast the news and events to its customers. With good and broad advertisement, the media can be heavily affected by the league brand and its personality. Also, holding of more matches lay the groundwork for building a desirable personality for the league by facilitating sponsorship grounds (to win the trust and confidence of sponsors) and concluding timed contracts with them. By conducting friendly games aimed at aiding the needy, complying with federation laws and regulations, and protecting community sports and such activities, the League organization accept its social responsibility towards the people, and promote its social character in the minds of the people. The league organization can also make the league more attractive with the use of prominent teams with star players and coaches, renowned and professionals referees; attractiveness is a qualitative factor that affects brand personality (5).

With fan-oriented strategic plans, the league organization can enhance its sporting events and create a distinctive and attractive personality for its customers. The league organization should address the infrastructure of its stadiums as well as the quality of all activities for the development inside the stadium before, during and after the matches.

Through successful management of the attributes and categories achieved and applying strategies, the Soccer club managers and planners can obtained the consequences by developing the brand personality of soccer league. These consequences include more loyal communication, further profits and revenue, identification of given potentials to customer and, ultimately, increased league brand power. Enabling marketers to design advertisement campaigns to attract customers to the league brand is also one of the consequences. 


\section{CONCLUSION}

As a general summary and conclusion of the research findings, it can be argued that sustainable brand personality occurs when there are desirable consequences of the brand personality of soccer league, and this occurs when the identified concepts are realized. Therefore, short-term and cross-sectional view should be avoided and replaced with a systematic and holistic view. One of the main purposes of customer relationship management is to build customer relationships and the length of the relationship; the brand personality is a safe strategy for the establishment of these two important issues. Communicating with a customer is crucial in sports events, because in the absence of the customer's passion and enthusiasm, it will not be beneficial to hold marketers' competitions and activities. Thus, identifying the factors and resources that contribute to creating a brand personality is necessary. Where the league brand personality represents its logical aspect, the desirable league brand personality can show the emotional aspect of the league and create remarkable "self-expression" values for the league, and this activity leads to attraction of customers, winning their trust and increasing their loyalty, especially their attitude. Thus, since the soccer league of the country has a few fans and these fans are more limited to the competition season, and also to meet the huge needs of soccer social capital in the country, the enthusiastic and elite managers are bound to enforce the right strategies to create the ideal personality for the league brand. The present research aimed to identify the growth and development components of League Brand personality, presenting the strategies and consequences; however, it has some limitations in this regard. The findings of the survey are from the viewpoint of male experts, the views of female managers and experts in the field of soccer were not considered, and women account for a large share of the country's population. Another limitation is that the current study did not address the gap between the current league brand personality and its favorable state. Therefore, for further research, researchers can investigate the gap between the current brand personality and the league's desirable brand, and consider the women's soccer community.

\section{APPLICABLE REMARKS}

- Through planning to develop the personality of the brand, managers and planners of the league can increase their brand power and attract and retain more customers.

- Through shaping of the league brand personality based on the culture and tradition of the people of the country, sport marketers can reduce the conflict of the soccer culture with the culture of the people and perhaps eliminate it in the long-term.

\section{REFERENCES}

1. Kang C, Bennett G, Peachey JW. Five dimensions of brand personality traits in sport. Sport Management Review. 2016 Aug 1;19(4):441-53.

2. Deheshti M, Adabi Firouzjah, J., Alimohammadi, H. The Relationship between Brand Image and Brand Trust in Sporting Goods Consumers Ann Appl Sport Sc. 2016; 4(3):27-34.

3. Lee C, Yang C, Hung H. Evaluating game-brand congruity and flow on brand personality by using Gamifying learning. Eurasia Journal of Mathematics Science and Technology Education. 2017 Jul 1;13(7):3083-97.

4. Masoomi H. The Relationship between Brand Personality dimensions and Consumer's Loyalty to Sports Brands in Rasht city. 2018.

5. Giroux M, Pons F, Maltese L. The role of perceived brand personality in promotion effectiveness and brand equity development of professional sports teams. International Journal of Sports Marketing and Sponsorship. 2017 May 2;18(2):180-95.

6. Kumar A. Story of Aaker's brand personality scale criticism: Historia de la crítica a la escala de personalidad de marca de Aaker. Spanish Journal of Marketing-ESIC. 2018 Apr 18.

7. Aaker JL. Dimensions of brand personality. Journal of marketing research. 1997 Aug 1:347-56.

8. Braunstein JR, Ross SD. Brand personality in sport: Dimension analysis and general scale development. Sport Marketing Quarterly. 2010 Mar 1;19(1):8. 
9. Tsiotsou R. Developing a scale for measuring the personality of sport teams. Journal of Services Marketing. 2012 Jun 29;26(4):238-52.

10. Schade M, Piehler R, Burmann C. Sport club brand personality scale (SCBPS): A new brand personality scale for sport clubs. Journal of Brand Management. 2014 Nov 1;21(7-8):650-63.

11. Asadollahi A, Heidarzadeh Hanzaee, K., Abdolvand, M., \& Reshadatjooh, H. . 2015). Developing a Scale Sport Brand Personality in Iranian Sport Teams. ,. Research Journal of Recent Sciences. 2015;4(11):83-7.

12. Stadler Blank AK, Joerg;Baumgartner,Hans. Brand personality of professional sports teams. 2016.

13. Plummer JT. How personality makes a difference. Journal of Advertising Research. 1984;24:27-31.

14. Gwin CF, Gwin CR. Product attributes model: A tool for evaluating brand positioning. Journal of Marketing theory and Practice. 2003 Apr 1;11(2):30-42.

15. Braunstein-Minkove JR, Ross SD. Brand Personalities across the Big Four: Positioning Leagues for Differentiation. The Journal of SPORT. 2013;2(2):2.

16. Sung Y, Kim J. Effects of brand personality on brand trust and brand affect. Psychology \& Marketing. 2010 Jul;27(7):639-61.

17. Wee TT. Extending human personality to brands: The stability factor. Journal of Brand Management. 2004 Apr 1;11(4):317-30.

18. Rezaii DolatAbadi H, Khazaii Pool J, Amani M. Impact of Brand Personality on Brand Loyalty with Investigating the Mediator Role of Brand Affect, Brand Trust and Brand Preference: Case Study Iran Khodro Company. Iranian Journal of Management Science. 2013; 8(29): 59-72.

19. Carlson BD, Donavan DT. Human brands in sport: Athlete brand personality and identification. Journal of Sport Management. 2013 May;27(3):193-206.

20. Klipfel JA, Barclay AC, Bockorny KM. Self-Congruity: A Determinant of Brand Personality. Journal of Marketing Development \& Competitiveness. 2014 Nov 1;8(3).

21. Sirgy MJ. Self-concept in consumer behavior: A critical review. Journal of consumer research. 1982 Dec 1;9(3):287-300.

22. Sirgy MJ, Grewal D, Mangleburg TF, Park JO, Chon KS, Claiborne CB, Johar JS, Berkman H. Assessing the predictive validity of two methods of measuring self-image congruence. Journal of the academy of marketing science. 1997 Jun 1;25(3):229.

23. Fournier S. Consumers and their brands: Developing relationship theory in consumer research. Journal of consumer research. 1998 Mar 1;24(4):343-73.

24. Keller KL, Lehmann DR. Brands and branding: Research findings and future priorities. Marketing science. 2006 Nov;25(6):740-59.

25. Fournier S. Consumers and their brands: Developing relationship theory in consumer research. Journal of consumer research. 1998 Mar 1;24(4):343-73.

26. Eisend M, Stokburger-Sauer NE. Brand personality: A meta-analytic review of antecedents and consequences. Marketing Letters. 2013;24(3):205-16.

27. Blank AS, Koenigstorfer J, Baumgartner H. Sport team personality: It's not all about winning!. Sport Management Review. 2018 Apr 1;21(2):114-32.

28. Shafaie L, Memari, Z., \& Asghari Jafarabadi, M. . The Brand Personality of Selected Iranian Football League Teams: Explaining Dimensions and Modeling Journal of Sport Management and Development. 2016;5(1):117-36.

29. Fisher RJ, Wakefield K. Factors leading to group identification: A field study of winners and losers. Psychology \& Marketing. 1998 Jan;15(1):23-40.

30. Oughton.C MJ. Competitive balance in football: Trends and effects. University of Landon), Football Governance Research Centre, researchpaper,. 2003;2.

31. Seimiene E, Kamarauskaite E. Effect of brand elements on brand personality perception. Procedia-Social and Behavioral Sciences. 2014 Nov 26;156:429-34.

32. Wu SH, Tsai CY, Hung CC. Toward team or player? How trust, vicarious achievement motive, and identification affect fan loyalty. Journal of Sport Management. 2012 Mar;26(2):177-91.

33. da Silva EC, Las Casas AL. Sport fans as consumers: An approach to sport marketing. British Journal of Marketing Studies. 2017 Apr;5(4):36-48.

34. Karjaluoto H, Munnukka J, Salmi M. How do brand personality, identification, and relationship length drive loyalty in sports? Journal of Service Theory and Practice. 2016 Jan 11;26(1):50-71.

35. Maehle N, Supphellen M. In search of the sources of brand personality. International Journal of Market Research. 2011 Jan;53(1):95-114. 